\title{
Project Training as the Basis for the Formation of Entrepreneurial Competencies
}

\author{
Kutsenko Svetlana Munavirovna \\ Department of Computer Science and Management \\ Information Systems \\ Kazan State Power Engineering University \\ Kazan, Russian Federation \\ s.koutsenko@mail.ru \\ Saltanaeva Elena Andreevna \\ Department of Computer Science and Management \\ Information Systems \\ Kazan State Power Engineering University \\ Kazan, Russian Federation \\ elena_maister@mail.ru
}

\author{
Malacion Svetlana Fialovna \\ Department of Physics \\ Kazan State Power Engineering University \\ Kazan, Russian Federation \\ sveta_malacion@mail.ru
}

\begin{abstract}
For the effective training of highly qualified specialists in any field of professional activity, it is necessary to develop entrepreneurial competencies. The article discusses the formation of entrepreneurial competencies among students of Kazan State Power Engineering University (KSEU) and presents the requirements of employers for future power engineers: basic technical education, a portfolio of achievements in educational activities, intellectual potential, experience in project activities, and entrepreneurial competencies. The definitions of project training and its implementation in the university are given on the example of the work of the student business incubator and the youth innovation center of KSEU. It is shown that the implementation of the project involves the use of innovative teaching methods and means, as well as the ability to apply knowledge from various fields of science, engineering, technology, economics and management.
\end{abstract}

Keywords: project training, project technology, entrepreneurial competencies, youth innovation center, student business incubator

\section{INTRODUCTION}

The future of any state is young people from 16 to 30 years old. The leadership of our country, realizing this fact, is spending more and more resources on their intellectual, physical and spiritual-moral development.

Federal state educational standards of the latest generation for the preparation of bachelors and masters require students to receive, along with academic competencies, additional professional and social competencies in a short time.
Technology and globalization have given free access to knowledge, but there is an opinion that technical higher education institutions are not flexible and are not able to give the necessary practical skills [1]. There is no connection between fundamental science and entrepreneurship. When students develop technology startups, they lack practical experience and understanding of the needs of the industry. They solve a technical problem, not a business problem. There should be interaction between higher education institutions and enterprises in the training of future specialists [2].

Successful entrepreneurs are the main driving force for the economy. The topic of youth entrepreneurship is today one of the priorities, society needs proactive youth, capable of creating and implementing innovative ideas [3]. In this regard, there is a need to support youth projects, to develop the institution of student self-government, to create programs for the formation of a personnel reserve for youth. Higher educational institutions need to look for ways and methods of forming in students not only the necessary professional knowledge and skills, but also their readiness for entrepreneurial activity.

The requirements of employers for graduates of technical, including energy, universities have changed. Standard skills for the employer are no longer enough, therefore, more and more often, requirements have been presented to applicants regarding their personal qualities.

First, employers need graduates who can cope with everyday duties, and are also able to prevent emergencies, propose new solutions, etc. 
Secondly, employers want the specialist to have a good basic education directly in the field of his professional activity.

Thirdly, a young specialist should be able to work in a team, enter professional communities and be aware of the latest events, new products, and changes in his field.

Fourth, employers prefer certified professionals.

Fifth, a modern graduate of a technical university should have competencies in the field of information technology in connection with the transition to the digital economy [4].

Sixth, employers want the young specialist to be ready for entrepreneurial activity to ensure the competitiveness of their company $[5,6,7]$.

Higher educational institutions face the task of developing entrepreneurial competences among students.

\section{MATERIALS AND METHODS}

One of the best ways to ensure the formation of entrepreneurial competencies is to include students in project activities from the first courses of study.

The use of technology of project training involves certain material and technical and organizational support. So, in addition to traditional lectures, seminars, such organizational forms as creative workshops, laboratories, design bureaus should take place, and the methodological support of the educational process from the perspective of design should be reviewed [8].

Project training forms the following skills in students:

- research skills (the ability to analyze a problem situation, identify problems. To carry out the selection of necessary information from the literature, observe practical situations, record and analyze their results. To construct hypotheses, implement, generalize, draw conclusions;

- the ability to work in a team (there is an awareness of the importance of teamwork to obtain a result, the role of cooperation, joint activities),

- communication skills (the ability not only to express one's point of view, but also to listen, to understand another. In case of disagreement, be able to constructively criticize the alternative approach in order to ultimately find a solution that synthesizes and retains the positives of each sentence) [9].

The implementation of a project is always a collective, creative, practical work designed to produce a specific product or scientific and technical result. Such work implies a clear, unambiguous formulation of the task, determining the timing of the implementation of the planned, determining the requirements (technical specifications) for the developed object. Work on the project should be carried out within the life cycle of any project: review work, research, technical task, design stage, etc. The main goal is to stimulate the cognitive activity of students, shifting the emphasis from academic knowledge to independent research and application of practical skills [10]. Joint problem solving in a team environment is an effective training method that contributes to the achievement of results, directly related to the quality of team decisions and individual training of working group members [11].

\section{Design technology involves the following steps:}

Stage 1. Choosing a research topic. It is important to find a task that is significant in theoretical, research, and technical terms, leading to the creation of a specific product when it is solved. This choice can be made by the student himself during an individual conversation with the leader, as a result of a discussion of the problem in the group, or suggested by the leader. The subjects of the projects may relate to some theoretical issue of the university program with the aim of deepening the knowledge of individual students on this issue, differentiating the learning process. If the topics of the projects relate to some practical issue relevant to everyday life, then the product being developed and the solutions must be original and novel. Since the work on the project requires attracting students' knowledge not in one subject, but from different areas, their creative thinking, research skills, this way knowledge integration is achieved and interdisciplinary connections are formed. At this stage, the goal, structure and outcome of the project are determined.

Stage 2. Formation of teams. To carry out work on the project, a team must be created. Roles and responsibilities are distributed among students. Here leadership qualities and the ability to work in a team are manifested, where each participant can try himself in one of the roles: the project participant is the executor of project tasks, the project developer is a "generator of ideas", the participant in setting problems, goals, defining design tools, speaker, etc. [12]. Joint problem solving in a team setting is an effective learning method.

Stage 3. Finding a solution. Project participants, working in a group, search for a solution to the problem in a certain sequence. At this stage, students master the skills and strategies necessary for compiling, analyzing and summarizing information. Hypotheses are put forward for the optimal solution of the problem by the "brainstorming" method, research methods are discussed, and work is carried out to complete the project itself. There is a discussion of how to present the results. Then the project participants analyze the results and draw conclusions about their work.

Stage 4. Presentation of the project. Each group "protects" its project, presents the results of its work in the form of an oral message, presentation or report, which should reflect the relevance of the topic, practical focus and significance of the work. At this stage, the quality of the report, the volume and depth of the speaker's knowledge, his argumentation, speech culture, sense of time, ability to hold the attention of listeners and conduct a discussion are evaluated. Design results can also be presented at exhibitions, as well as in the form of publications and reports at seminars and conferences.

Stage 5. Assessment of the project. The results of the work are summarized and the activity of each member of the working group is evaluated, during which the results of the 
KSEU Youth Business Incubator works in the following

project are collectively evaluated and checked, the reasons for success and failure are clarified, recommendations are made that can be used to expand the project in the future, the possibility of practical application of the results with the aim of possible commercialization of the results. The supervisor must control the project implementation process to help students successfully submit the final project result [13].

In the course of work on projects, students develop, in addition to project competencies, entrepreneurial competencies.

\section{RESULTS}

KSEU created the conditions for the formation of these competencies: the curriculum of all areas and profiles of bachelor training has introduced the optional "Project Activity" to organize students' independent work in the development of projects and in the future to prepare graduate qualification work carried out in the form of a diploma project by a team of students. In addition, the KSEU successfully operates a youth innovation center and a student business incubator.

The Youth Innovation Center YIC "Energy" of KSEU, established in 2012, is a center for students to implement their scientific projects and developments in the field of energy and housing and communal services.

The YIC attracts students of various specialties for internships, as well as for educational, industrial and scientific practice. The main conditions are determination and willingness to learn something new. During the internship or practice, students can develop skills in practical programming, 3D modeling, designing, website development, working with electronics, $\mathrm{CNC}$ machines, 3D printing, communication, teamwork, working with customers, sales, marketing, etc. The student can join an existing team (a robotics laboratory, a prototyping laboratory, a team for the development of radio frequency contactless devices, a team for developing online platforms, etc. The composition of teams is regularly updated), develop competencies in the chosen role, or start their own project. The plans of the YIC include an increase in the number of teams in the field of robotics with a further exit to work with enterprises in order to find problematic tasks that these teams can solve with the help of robotics, or with the exit to the creation of serial robotic products.

A youth business incubator (YBI) was created on the basis of YIC "Energy", which later grew into a separate structure.

The main task of the youth business incubator is to create a comfortable entrepreneurial ecosystem for young entrepreneurs of KSEU, help in the commercialization of intellectual property and support entrepreneurial initiatives of students and graduate students. YBI solves problems of different levels: the search for investments for student projects, overcoming the legal and financial illiteracy of novice entrepreneurs and young scientists, overcoming psychological barriers, creating conditions for the commercialization of students' scientific developments, attracting students to the process of creating, developing and implementing high-tech products or technologies. areas:

- motivational, within the framework of which the project "100 Questions for a Successful Person" was developed with the invitation of famous and successful people from different fields;

- an educational one, within the framework of which a business school was created with the invitation of business trainers who teach how to generate, test business ideas, understand legal and accounting intricacies for entrepreneurs, develop skills in negotiations, time management, oratory and team building;

- project, in the framework of which direct work on the project is carried out by team members with the distribution of roles;

- entrepreneurial, in the framework of which a business incubator helps to finalize the idea to the stage of commercialization, find mentors and experts, attract investments, provide support and assistance in preparing for competitions and grants.

Students actively participate in competitions for grants in various programs of the Russian, republican and municipal levels: applications for grant projects in the framework of "50 innovative ideas", Algarysh, for a grant in the framework of the federal program "U.M.N.I.K." and etc. Business incubator supports ideas that correspond to priority areas: energy, industry, IT and others.

Project activities in the process of mastering the educational program and work in the YIC and YBI for the student are:

- the ability to maximize your creative potential;

- activities that allow you to prove yourself individually or in a group, try your hand, apply knowledge, bring benefits, show the achieved result;

- work aimed at solving an interesting problem, when the result of this activity, the found method of solving the problem, is practical and has an applied value;

- the formation of entrepreneurial competencies: the ability to generate business ideas, assess the prospects of market opportunities for the implementation of projects, develop business plans for creating activities [14];

- the ability to establish contacts, enter into effective transactions, carry out communications with different partners;

- the ability to find innovative solutions to problems in standard and non-standard situations;

- an interactive form of training for the formation of innovative research competence [15];

- the use of innovative teaching methods and means, as well as the ability to apply knowledge from various 
- the formation of interpersonal skills and teamwork. and management.

\section{DISCUSSION}

There is currently no clear definition of entrepreneurial competencies. We are close to the position of the authors A.E. Gutkevich, S.L. Eremina [16], which provide a list of the main competencies of an entrepreneur in the field of engineering projects:

1) planning and organization of work in the team: draws up long-term plans for the team's work, correctly distributes efforts when working with several team members, clearly sets goals at each stage of the team's work, analyzes the results of work at each stage, on this basis plans further activities of the team;

2) result orientation: independently sets complex goals, constantly raises the bar of self-requirements, stoutly and persistently overcomes difficulties, achieves excellence, makes efforts to obtain a high-quality result, takes personal responsibility for the results;

3) communication and business communication: when presenting information, clearly and consistently conveys his ideas, knows how to establish contact with people of various types, defends his point of view reasonably, works effectively with objections [17];

4) understanding of the business: he knows the specifics of the market of engineering ideas, uses the information on the actions of competitors and market trends and scientific and technological progress in his work, understands the features of the business, has a holistic view of the engineering and entrepreneurial project, thinks in terms of commercial benefits.

We believe that it is necessary to expand this list by adding project competencies, and the following ones to personal competencies: risk taking, ambition, stress tolerance, leadership, performing discipline, high motivation. [18, 19, 20].

\section{CONCLUSION}

Project activities can be useful in research work, as the implementation of a scientific project increases the motivation for learning, and also contributes to:

- increasing the value of learning;

- the acquisition of knowledge beyond the scope of the training program;

- mastering valuable research skills and abilities;

- better absorption of the material;

- development of skills of comparison, classification, analysis and synthesis; - the acquisition of skills for transferring knowledge to another context;

- the development of the ability to search and analyze information;
Thus, it was revealed that the application of the project method was one of the factors of formation and development of entrepreneurial competences among graduates of Kazan State Energy University.Thus, the organization of the student's project activities is one of the factors in the development of entrepreneurial competence. Such experience at the Kazan State Energy University is carried out through the practical implementation of student projects. The use of innovative technologies in the educational process, attracting students to independent entrepreneurial activities within the framework of the YIC and YBI will prepare them for future professional activities.

These professional skills will testify to the achievement of one of the tasks of engineering education - the formation of design and entrepreneurial competencies in the chosen field of knowledge.

\section{REFERENCES}

[1] R. Singh Dubey, V. Tiwari, "Operationalisation of soft skill attributes and determining the existing gap in novice ICT professionals", International Journal of Information Management, vol. 50, pp. 375-386, February 2020.

[2] A.A. Kaybiyaynen, V.V. Nasonkin, D.V. Bondarenko, A.V. Nazarov, G.F. Tkach, "Networking Between Engineering University and Enterprises in Future Students Training", Advances in Intelligent Systems and Computing, vol. 916, 2020, pp. 503-513, 21st International Conference on Interactive Collaborative Learning, ICL 2018.

[3] S.E. Weber, S. Funke, "An «instructional» perspective on entrepreneurship education - focusing on the development of team competencies", Empirical Research in Vocational Education and Training, vol. 4, Issue 1, pp. 49-72, 2012

[4] E.A. Saltanaeva, R.I. Eshelioglu, "The Use of New Information Technologies in Education", NovaUm.Ru, No. 12, pp. 224-226, 2018.

[5] D. Borah, K. Malik, S. Massini, "Are engineering graduates ready for R\&D jobs in emerging countries? Teaching-focused industry-academia collaboration strategies", Research Policy, vol. 48, Issue 9, November 2019.

[6] G. Marbach-Ad, C. Hunt, K.V. Thompson, "Exploring the Values Undergraduate Students Attribute to Cross-disciplinary Skills Needed for the Workplace: an Analysis of Five STEM Disciplines", Journal of Science Education and Technology, vol. 28, Issue 5, pp. 452-469, 1 October 2019

[7] R. Martin-Rojas, V.J. Garcia-Morales, N. Gonzalez-Alvarez, "Technological antecedents of entrepreneurship and its consequences for organizational performance", Technological Forecasting and Social Change, vol. 147, pp. 22-35, October 2019.

[8] V.A. Kapranova, "Project-based training at the university: historical and technological aspects", Izvestiya VGPU, No. 3 (264), pp. 78-80, 2014.

[9] E.S. Polat, "Project Method: Scientific and Methodological Collection", Ed. M.A. Gusakovsky; Belarusian State University: Center for the Development of Education, Minsk, pp. 39-38., 2003.

[10] M. Salnikova, Y. Salnikova, M. Soroka, V. Stolyarova, "Students' Independent Learning Activity as an Effective Method of Acquiring Professional Competencies", Advances in Intelligent Systems and Computing, vol. 963, 2020, pp. 391-399, AHFE International Conference on Human Factors in Training, Education, and Learning Sciences, 2019.

[11] M. Menekse, S. Purzer, D. Heo, “An investigation of verbal episodes that relate to individual and team performance in engineering student teams", International Journal of STEM Education, vol. 6, Issue 1, 1 December 2019 
[17] D. Seth, G.N. Carryon, “Investigating undergraduate students' communication self-efficacy during an engineering design course", 7th IEEE Frontiers in Education Conference, FIE 2017, pp. 1-94, 12 December 2017. for Lesson and Learning Studies, vol. 3, Issue 1, pp. 80-99, 20 December 2013.

[13] S.M. Kutsenko, S.F. Malacion, "On the issue of project-based learning", Scientific notes of the Institute of Social and Humanitarian Knowledge, Issue No. 2 (16), pp. 128-131, 2018.

[14] F. Sirelkhatim, Y. Gangi, "Entrepreneurship education: A systematic literature review of curricula contents and teaching methods", Cogent Business and Management, vol. 2, Issue 1, 31 December 2015.

[15] J.V. Torkunova, "Optimization Model of Interactive Forms of Education for Formation Innovative and Research Competence", Procedia - Social and Behavioral Sciences, vol. 191, pp. 1690-1692, 2 June 2015.

[16] A.E. Gutkevich, S.L. Eremina, "Experience in the formation of managerial competencies", Bulletin of Tomsk Polytechnic University, vol. 319, No. 6, pp. 24-28, 2011.

[18] R.L.D. Moura, T.C.J. Carneiro, B.D. Diniz, "Influence of the project manager's personal characteristics on project performance", Gestao e Producao, vol. 25, Issue 4, pp. 751-763, October-December 2018.

[19] J.L.S. Chandler, "Leadership in Action: Sharing Leadership in an Engineering Research Center", Journal of Professional Issues in Engineering Education and Practice, vol. 144, Issue 4, 1 October 2018.

[20] H. Ni, Y. Ye, "Entrepreneurship Education Matters: Exploring Secondary Vocational School Students' Entrepreneurial Intention in China", Asia-Pacific Education Researcher, vol. 27, Issue 5, pp. 409418, 1 October 2018. 